\title{
$\overbrace{}^{2}$ \\ POLITEKNIK NEGERI PADANG \\ JuRNAC Taquil $M_{\text {esin }}$ \\ Vol. 14 No. 2 (2021) 94 - 98 \\ ISSN Media Elektronik: 2655-5670
}

\section{Analisis Kebutuhan Debit Air Di Gedung C RSUD Kota Bukittinggi}

\author{
Mela Rizki Angraini ${ }^{1}$, Muchlisinalahuddin ${ }^{2}$, Riza Muharni ${ }^{3}$ \\ 1,2,3 Teknik Mesin, fakultas Teknik, Universitas muhammadiayah Sumatera Barat \\ 1'melarizkiangraini02@gmail.com ${ }^{2}$ muchlisinalahuddin.tm98@gmail.com ${ }^{3}$ kaizaaqeelaasha@gmail.com
}

\begin{abstract}
In the Bukittinggi City Hospital building which has 6 floors, there is a water pump and a reservoir used to supply clean water for daily needs. Based on the reality in the field where there is no secondary data to determine the type of pump and reservoir. The purpose of this analysis is to obtain clean water discharge requirements, obtain the type of pump and ensure that the reservoir used for building C RSUD Kota Bukittinggi is in accordance with the type of pipe and reservoir installed in building $\mathrm{C}$, floor 6 . By using field studies and interviews and applying the formulas related to pump calculations. In determining the type of pump to be used in the building, it includes the required water discharge, determining the capacity of the components to be used such as pipe diameter, water tank capacity on the ground floor and roof of the building and the total head on the pipe. Based on the calculation results, the required water discharge is $0.08333 \mathrm{~m} 3 / \mathrm{min}$, the upper reservoir has a capacity of 150,000 liters, the bottom reservoir is 5,000 liters and the Hot that occurs is $18.429 \mathrm{~m}$. Then the required pump specifications are $40 \times 32 \mathrm{~B} 2-51.5$ Grundfos CM 10-3. The pump specifications are not much different from those that have been applied in the field.
\end{abstract}

Keywords: Building, Pump, Tank.

\begin{abstract}
Abstrak
Pada Gedung C RSUD Kota Bukittinggi yang memiliki 6 lantai, terdapat pompa air dan bak penampung yang digunakan untuk mensuplai air bersih untuk kebutuhan sehari-hari. Berdasarkan kenyataan dilapangan dimana tidak ada data-data sekunder untuk menentukan jenis pompa dan bak penampung tersebut. Tujuan analisa ini untuk mendapatkan kebutuhan debit air bersih, mendapatkan jenis pompa dan memastikan bak penampung yang digunakan untuk gedung C RSUD Kota Bukittinggi sudah sesuai dengan jenis pipa dan bak penampung yang terpasang digedung $\mathrm{C}$ berlantai 6 . Dengan menggunakan metode studi lapangan dan wawancara serta penerapan rumus-rumus yang berhubungan dengan perhitungan pompa. Dalam menentukan jenis pompa yang akan digunakan pada gedung tersebut meliputi debit air yang dibutuhkan, menentukan kapasitas komponen-komponen yang akan digunakan seperti diameter pipa, kapasitas tangki air dilantai dasar dan di atap gedung dan head total pada pipa. Berdasarkan hasil perhitungan, debit air yang dibutuhkan $0,08333 \mathrm{~m} 3 / \mathrm{min}, \mathrm{bak}$ penampung atas dengan kapasitas 150.000 liter, bak penampung bawah 5.000 liter dan Htot yang terjadi adalah 18,429 m. Maka spesifikasi pompa yang diperlukan adalah $40 \times 32 \mathrm{~B}_{2}-51,5$ Grundfos CM 10-3 . spesifikasi pompa tersebut tidak jauh berbeda dengan yang sudah diterapkan di lapangan
\end{abstract}

Kata kunci: Gedung, Pompa, Bak penampung.

\section{Pendahuluan}

Air merupakan salah satu kebutuhan utama dalam kehidupan sehari-hari. Manusia binatang dan tumbuhan memerlukan air untuk kelangsungan hidupnya. Air dapat pula digunakan sebagai pelarut, pembersih dan keperluan lai seperti rumah tangga, industri maupun pemanfaatan energi. Untuk mengoptimalkan aliran air agar memenuhi kebutuhan yang didinginkan, maka diperlukan pompa, bak penampung yang sesuai dan effisiensi dalam mensuplai air tersebut. Berdasarkan kenyataan di lapangan, dimana tidak terdapat data-data sekunder yang bisa mendukung proses maintenance, juga untuk mengetahui kebutuhan air bersih dan kebutuhan bak penampung yang diperlukan oleh gedung $\mathrm{C}$ berlantai 6 di RSUD Kota Bukittinngi.

\subsection{Debit Air}

Debit air adalah kecepatan aliran zat cair melewati jarak penampang pe satuan waktu. Debit air menggunakan satuan volume per waktu atau 
liter/detik, $\mathrm{m}^{3} /$ detik, liter $/ \mathrm{jam} / \mathrm{m}^{3} / \mathrm{jam}$ dan berbagai satuan lainnya.

Formula ditulis secara jelas menggunakan equation dengan indeks 1.

$Q=\frac{V}{t}$

1.2 Bak Penampung

Yang dimaksud dengan reservoir disini adalah tempat penampung air bersih, pada sistem penyediaan air bersih.

\subsection{Sistem Pemipaan}

Sistem pemipaan adalah suatu sistem jaringan pipa yang terpasang pada suatu rangkaian yang mempunyai fungsi untuk menyalurkan fluida. Komponen dalam system pemipaan meliputi pipa, flange, fitting, gasket, valve, dan bagian-bagian dari komponen pemipaan lainnya. Berikut komponen sistem pemipaan [1].

a) Pipa

Pipa yaitu didefinisikan sebagai lingkaran panjang dari logam, metal, kayu dan seterusnya yang berfungsi untuk mengalirkan fluida (air, gas, minyak dan cairan lainnya) dari suatu tempat ke tempat lain sesuai dengan kebutuhan yang dikehendaki.

b) Nominal Pipe size (NPS)

Nominal Pipe Size (NPS) adalah penanda ukuran pipa berdimensi. Hal ini menunjukkan standar ukuran pipa bila diikuti dengan jumlah penunjukan ukuran tertentu tanpa simbol inch. Ukuran Nominal Pipe size (NPS) bisa dilihat pada Tabel 1 .

Tabel 1. Pipa size designators: Nps dan DN

\begin{tabular}{|c|c|c|c|c|c|c|c|c|c|c|c|}
\hline \multirow{2}{*}{$\begin{array}{l}\text { NPS } \\
\text { lesignator }\end{array}$} & \multirow{2}{*}{$\begin{array}{c}\text { ON } \\
\text { Designator }\end{array}$} & \multicolumn{2}{|c|}{$\begin{array}{c}\text { Outside } \\
\text { Diameter }\end{array}$} & \multicolumn{2}{|c|}{$\begin{array}{l}\text { Inside } \\
\text { Diameter }\end{array}$} & \multicolumn{2}{|c|}{$\begin{array}{c}\text { Wall } \\
\text { Thickness }\end{array}$} & \multicolumn{4}{|c|}{ Nominal Weight (Mass) per unit Length } \\
\hline & & (Inches) & $(\mathrm{mm})$ & (Inches) & $(\mathrm{mm})$ & |(Inches) & $(\mathrm{mm})$ & \begin{tabular}{|c|c|}
$\begin{array}{c}\text { Plain End } \\
\text { (bifit) }\end{array}$ \\
\end{tabular} & $\begin{array}{c}\text { Plain End } \\
(\mathrm{kg} / \mathrm{m})\end{array}$ & \begin{tabular}{|c} 
Threads 87 \\
Couplings \\
$($ bitit)
\end{tabular} & $\begin{array}{l}\text { Threads \& } \\
\text { Couplings } \\
\text { (kogmm }\end{array}$ \\
\hline $1 / 8$ & 6 & 0.405 & 10.3 & 0.269 & 6.8 & 0.068 & 1.73 & 0.24 & 0.37 & 0.25 & 0.37 \\
\hline $1 / 4$ & 8 & 0.540 & 13.7 & 0.364 & 9.2 & 0.088 & 2.24 & 0.43 & 0.63 & 0.43 & 0.63 \\
\hline 38 & 10 & 0.675 & 17.1 & 0.493 & 12.5 & 0.091 & 2.31 & 0.57 & 0.84 & 0.57 & 0.84 \\
\hline $1 / 2$ & 15 & 0.840 & 21.3 & 0.622 & 15.8 & \begin{tabular}{|l|l|} 
\\
\end{tabular} & 2.77 & 0.85 & 1.27 & 0.86 & 1.27 \\
\hline $3 / 4$ & 20 & 1.050 & 26.7 & 0.824 & 20.9 & 0.113 & 2.87 & 1.13 & 1.69 & 1.14 & 1.69 \\
\hline 1 & 25 & 1.315 & 33.4 & 1.049 & 26.6 & \begin{tabular}{|l|l|}
0.133 \\
\end{tabular} & 3.38 & 1.68 & 2.50 & 1.69 & 2.50 \\
\hline 1.1/4 & 32 & 1.660 & 42.2 & 1.380 & 35.1 & \begin{tabular}{|l|l|}
0.140 \\
\end{tabular} & 3.56 & 2.27 & 3.39 & 2.28 & 3.40 \\
\hline $1-1 / 2$ & 40 & 1.900 & 48.3 & 1.610 & 40.9 & \begin{tabular}{|l|l}
0.145 \\
\end{tabular} & 3.68 & 2.72 & 4.05 & 2.74 & 4.04 \\
\hline 2 & 50 & 375 & 60.3 & 2.067 & 52.5 & 0.154 & 3.91 & 66 & 5.44 & 3.68 & 5.46 \\
\hline $2 \cdot 1 / 2$ & 65 & 2.875 & 73.0 & 2.469 & 62.7 & \begin{tabular}{|l|l|}
0.203 \\
\end{tabular} & 5.16 & 5.80 & 8.63 & 5.85 & 8.67 \\
\hline 3 & 80 & 3.500 & 88.9 & 3.068 & 77.9 & \begin{tabular}{|l|l|}
0.216 \\
\end{tabular} & 5.49 & 7.58 & 11.29 & 7.68 & 11.35 \\
\hline $3 \cdot 1 / 2$ & 90 & 4.000 & 101.6 & 3.548 & 90.1 & 0.226 & 5.74 & 9.12 & 13.57 & 9.27 & 13.71 \\
\hline 4 & 100 & 4.500 & 114.3 & 4.026 & 102.3 & \begin{tabular}{|l|l|}
0.237 \\
\end{tabular} & 6.02 & 10.80 & 16.07 & 10.92 & 16.23 \\
\hline 5 & 125 & 5.563 & 141.3 & 5.047 & 158.2 & 0.258 & 6.55 & 14.63 & 21.77 & 14.90 & 22.07 \\
\hline 6 & 150 & 6.625 & 168.3 & 6.065 & 154.1 & 0.280 & 7.11 & 18.99 & 28.26 & 19.34 & 28.58 \\
\hline 8 & 200 & 8.625 & 219.1 & 7.981 & 202.7 & 0.322 & 8.18 & 28.58 & 42.55 & 29.35 & 43.73 \\
\hline 10 & 250 & 10.750 & 273.0 & 10.020 & 254.5 & 0.365 & 9.27 & 40.52 & 60.29 & 41.49 & 63.36 \\
\hline \multicolumn{12}{|c|}{ Standard Pipe } \\
\hline 121 & 300 & 12.750 & 323.8 & \begin{tabular}{|l|}
12.000 \\
\end{tabular} & 304.8 & 0.375 & 9.52 & 49.61 & 73.78 & 51.28 & 76.21 \\
\hline
\end{tabular}

c) Flange

Flange adalah sebuah mekanisme, yang menyambungkan antar element pemipaan. Fungsinya flange, agar element tersebut lebih mudah dibongkar pasang tanpa mengurangi kegunaan untuk mengalirkan fluida pada pressure yang tinggi.

\section{d) Valve}

Katup atau valve, adalah sebuah alat untuk mengatur aliran suatu fluida dengan menutup membuka atau menghambat laju aliran fluida.

\section{e) Fitting}

Fitting adalah salah satu komponen pemipaan yang memiliki fungsi untuk merubah, menyebarkan, membesar atau mengecilkan aliran. Fitting merupakan salah satu pemain utama dalam pemipaan. Fitting bukanlah nama untuk individu, melainkan nama yang digunakan untuk pengelompokan. Ini bisa dilihat pada Gambar 1.

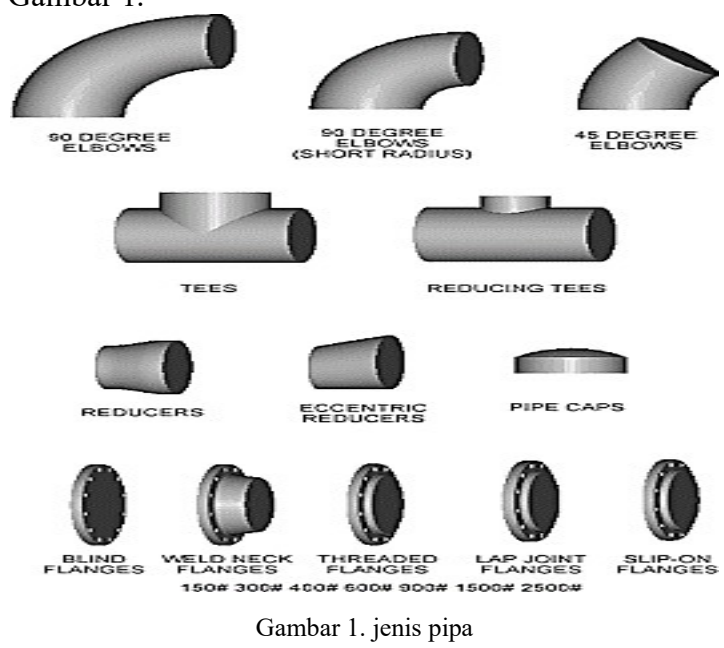

1.4 Pompa

Pompa adalah suatu alat yang digunakan untuk memindahkan suatu cairan dari suatu tempat ke tempat lain dengan cara mengalirkan fluida. Kenaikan tekanan cairan tersebut dibutuhkan untuk mengatasi hambatan-hambatan selama pengaliran. Satu sumber umum mengenai terminology, definisi, hukum dan standar pompa adalah Hydraulic Institute Standards dan telah disetujui oleh American National Standards Institute (ANSI) sebagai standar internasional.

\subsection{Klasifikasi pompa}

Klasifikasi pompa berdasarkan tipe didefinisikan oleh Hydraulic Institute. Klasifikasi pompa bisa dilihat pada Gambar 2.

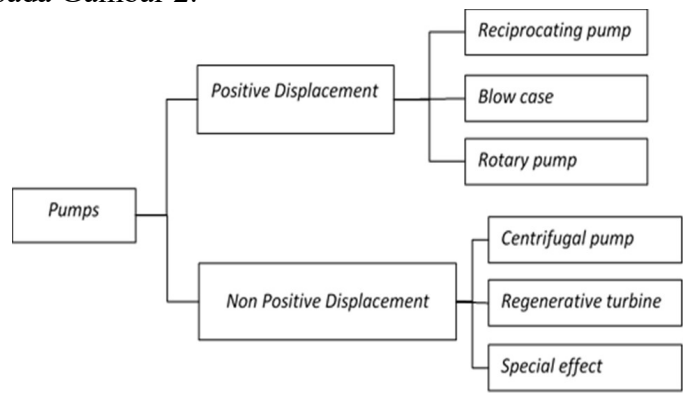

Gambar 2. Klasifikasi Pompa 
1.6 Pompa Sentrifugal (Centrifugal Pump)

Pompa sentrifugal merupakan pompa non positive displacement yang menggunakan gaya sentrifugal untuk menghasilkan head untuk memindahkan zat cair [2]. Ini tergambar pada Gambar 3.

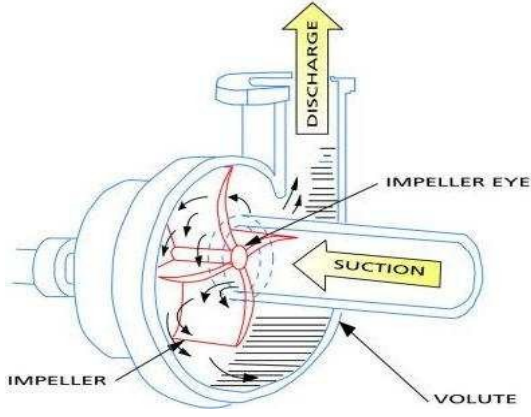

Gambar 3. Pompa Sentrifugal

\subsection{Sifat Aliran Fluida Pada Pipa}

a) Aliran Laminer

Aliran fluida jenis ini akan terjadi apabila kecepatan fluida yang mengalir melalui pipa rendah, maka gerakan alirannya akan konstan (steady) baik besarnya maupun arahnya pada sembarang titik. Aliran laminer dapat diketahui dari perhitungan Reynold Number.

$$
R_{e}=\frac{\rho \cdot v \cdot D}{\mu}
$$

b) Aliran Turbulen

Aliran ini terjadi apabila kecepatan fluida tinggi, aliran tidak lagi steady namun bervariasi baik besar maupun arahnya pada sembarang titik. Aliran akan bersifat turbulent jika hasil perhitungan Reynold Number $\left(R_{e}\right)$ diatas 4000 ( $R e>4000$, aliran turbulen) [3].

\subsection{Kavitasi}

Kavitasi adalah gejala menguapnya zat cair yang mengalir, karena tekanananya berkurang sampai dibawah tekanan uap jenuhnya sehingga akan timbul gelembung-gelembung uap zat cair. Jika pompa dijalankan terus-menerus dalam keadaan kavitasi, akan menyebabkan kerusakan terhadap area impeler, sehingga pada akhirnya terjadi erosi. Turunnya performance, timbulnya suara dan getaran, serta rusaknya pompa merupakan kerugian-kerugian dari timbulnya kavitasi.
1.9 Kapasitas Aliran Air

Jumlah air yang mengalir dalam satuan volume perwaktu. Besarnya debit dinyatakan dalam satuan meter kubik per detik $\left(\mathrm{m}^{3} / \mathrm{s}\right)$.

\section{Metode Penelitian}

Sistematika penelitian ini digambarkan dalam diagram alir pada Gambar 4 diagram alir penelitian.

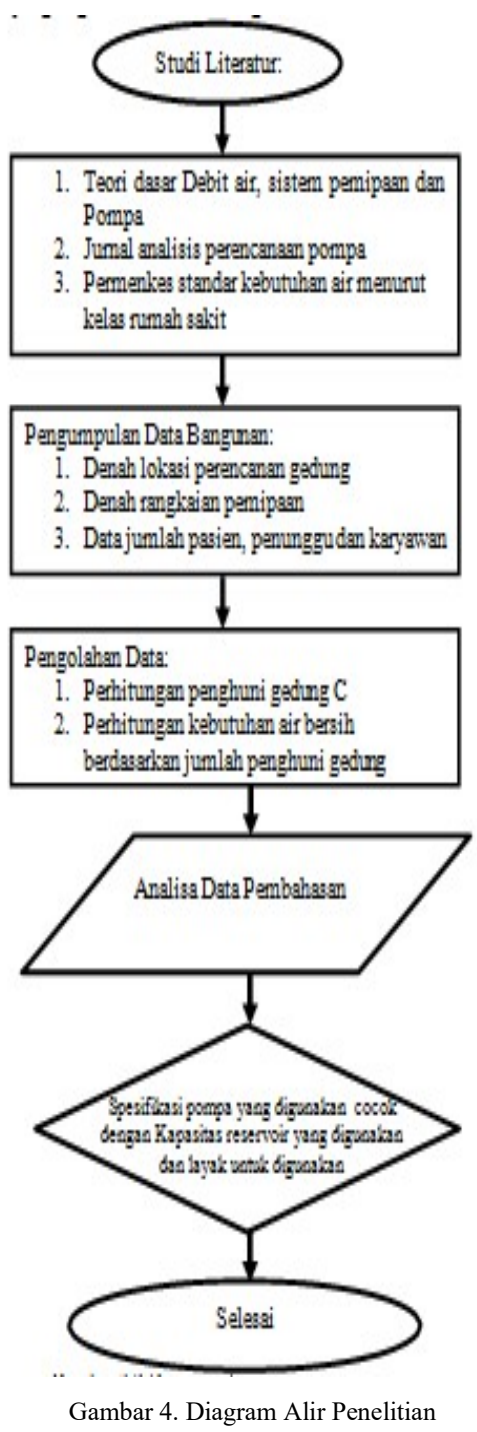




\section{Hasil dan Pembahasan}

a) Data pemakaian air digedung C RSUD Kota Bukittinngi.

Minimum volume air yang disediakan oleh rumah sakit pertempat tidur perhari dibedakan antara rumah sakit kelas A dan B dengan rumah sakit kelas $\mathrm{C}$ dan $\mathrm{D}$, karena perbedaan jenis layanan kesehatan yang antar ke dua kelas rumah sakit tersebut seperti yang tercantum dalam Tabel 2.

Tabel 2. Standar kebutuhan air menurut kelas rumah sakit dan jenis rawat.

\begin{tabular}{|l|l|l|l|l|}
\hline No & $\begin{array}{c}\text { Kelas } \\
\text { Rumah } \\
\text { Sakit/Jenis } \\
\text { Rawat }\end{array}$ & SBM & Satuan & Keterangan \\
\hline 1 & $\begin{array}{l}\text { Semua } \\
\text { Kelas }\end{array}$ & $\begin{array}{l}5- \\
7,5\end{array}$ & L/TT/Hari & $\begin{array}{l}\text { Kuantitas air } \\
\text { minum }\end{array}$ \\
\hline 2 & A - B & 400 & L/TT/Hari & $\begin{array}{l}\text { Kuantitas air } \\
\text { untuk } \\
\text { keperluan } \\
\text { higiene dan } \\
\text { sanitasi }\end{array}$ \\
\hline 3 & C-D & 200 & L/TT/Hari & $\begin{array}{l}\text { Kuantitas air } \\
\text { untuk } \\
\text { keperluan } \\
\text { higiene dan } \\
\text { sanitasi }\end{array}$ \\
\hline 4 & $\begin{array}{l}\text { Rawat } \\
\text { Jalan }\end{array}$ & 5 & L/TT/Hari & $\begin{array}{l}\text { Termasuk } \\
\text { dalam SBM } \\
\text { volume air } \\
\text { sesuai kelas } \\
\text { RS }\end{array}$ \\
\hline
\end{tabular}

Data jumlah penghuni merupakan data jumlah karyawan, penginap dan pengunjung. Data ini digunkan untuk menghitung jumlah pemakaian air berdasarkan jumlah penghuni pada RSUD Kota Bukittinggi. Data jumlah karyawan dapat dilihat pada Tabel 3.

Tabel 3. Jumlah penghuni gedung C RSUD Kota Bukittinggi

\begin{tabular}{|c|l|}
\hline Penghuni & Jumlah \\
\hline Tempat Tidur & 100 orang \\
\hline Penunggu & 100 orang \\
\hline Karyawan & 200 orang \\
\hline Total & 400 orang \\
\hline
\end{tabular}

perhitungan

a. Menentukan debit air

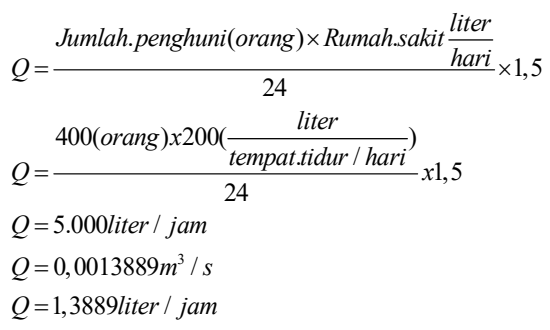

1) Reservoir bawah

$V_{b}=Q \times \frac{m^{3}}{\sec } \times 3600 \mathrm{sec} \times 24 \times 1,25$

$V_{b}=0,0013889 \frac{m^{3}}{\mathrm{sec}} \times 3600 \mathrm{sec} \times 24 \times 1,25$

$V_{b}=150 m^{3}$

$V_{b}=150.000 \mathrm{ltr}$

Sehingga ukuran reservoir bawah untuk memenuhi kebutuhan air bersih di RSUD yaitu dengan kapasitas 150.000 liter.

2) Reservoir atas

$V_{a}=Q \times \frac{m^{3}}{\mathrm{sec}} \times 3600 \mathrm{sec}$

$V_{a}=0,0013889 \frac{\mathrm{m}^{3}}{\mathrm{sec}} \times 3600 \mathrm{sec}$

$V_{a}=5,005 m^{3}$

$V_{a}=5.005 \mathrm{ltr}$

Sehingga ukuran reservoir atas untuk memenuhi kebutuhan air bersih di RSUD yaitu dengan kapasitas 5.000 liter.

c. Menentukan jenis pompa

berdasarkan hasil perhitungan yang dilakukan maka Head Total yang terjadi:

$H_{t o t}=h_{a}+\Delta h_{p}+h_{i}+\frac{v^{2}}{2 . g}$

$H_{t o t}=18+0+0,37257+\frac{1,057^{2}}{2 \times 9,8}$

$H_{t o t}=18,429$

Dari hasil perhitungan maka didapatkan:

Debit air $\mathrm{Q}=0,08333 \mathrm{~m}^{3} / \mathrm{min}$

$\mathrm{H}_{\text {tot }}=18,429 \mathrm{~m}$

Berdasarkan diagram pemilihan pompa standart maka didapatkan pompa dengan spesifikasi seperti ditunjukkan pada Gambar 5. Pompa yang dipilih adalah: $40 \times 32 \mathrm{~B}_{2}-51,5$. Arti kode tersebut adalah:

- 40

$=$ diameter isap $(40 \mathrm{~mm})$

- 32

= diameter buang $(32 \mathrm{~mm})$

- $\mathrm{B}$

$=$ type gedung

- Jumlah katub =2, katubnya 2 dan 3000 rpm

- 5

$=$ frekuensi $(50 \mathrm{~Hz})$

- Daya motor $=1,5 \mathrm{~kW}$

b. Menentukan ukuran bak penampung 


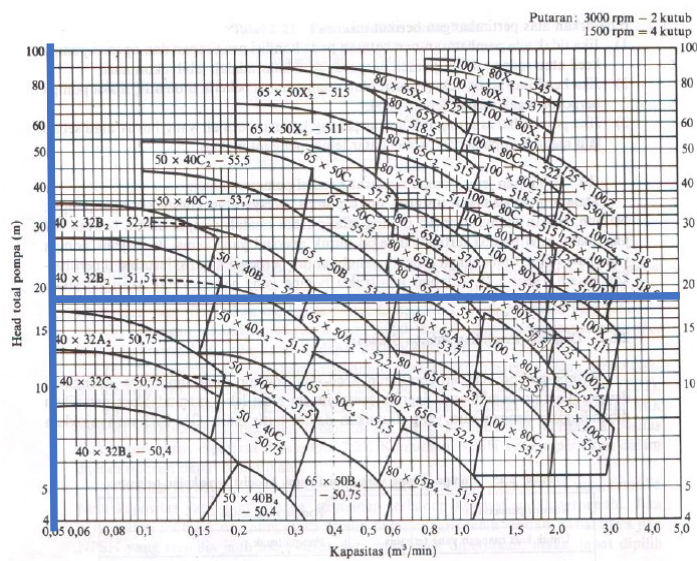

Gambar 5. Diagram pemilihan pompa.

\section{Kesimpulan}

Berdasarkan hasil dari estimasi jenis pompa untuk gedung berlantai 6 pada Rumah Sakit Umum Daerah Kota Bukittinggi maka dapat di simpulkan sebagai berikut:

- Debit air yang dibutuhkan RSUD Kota Bukittinggi adalah $0,08333 \mathrm{~m} 3 / \mathrm{min}$

- Kebutuhan reservoir bawah adalah 150.000 liter dan reservoir atas 5.000 liter

- $\quad$ Spesifikasi pompa yang sesuai untuk gedung C Rumah Sakit Umum

- Daerah Kota Bukittinggi adalah 40 x 32 B2 5

\section{1,5 grundfos CM 10-3}

- Head total hasil perhitungan sebesar 18,429 m. Sedangkan pompa yang terpasang berjumlah 2 unit. Sehingga pompa yang digunakan (masih belum bisa memenuhi kebutuhan pada sistem dengan baik).

\section{Daftar Rujukan}

[1] Anis,S.,\& Karnowo.(2008). Dasar Pompa. In Buku Ajar

[2] Candra, R. (2018). Perancangan Pompa Sentrifugal Dan Diameter Luar Impeller Untuk Kebutuhan Air Kapasitas 60 LPM di gedung $\mathrm{F}$ dan $\mathrm{D}$ Universitas Muhammadiyah Tanggerang.

[3] Muliawan, A., \& Yani, A. (2018). Analisa Head Mayor dan Minor Pompa Chiller dengan Bukaan Katup Instalasi Pompa Tunggal.

[4] Tukiman, Santoso, P., \& Satmoko, A. (2013). Perhitungan dan pemilihan pompa pada instalasi pengolahan air bebas mineral iradiator mamma kapasitas $200 \mathrm{Kci}$.

[5] Ubaedilah, U. (2017). Analisa Kebutuhan Jenis Dan Spesifikas Pompa Untuk Suplai Air Bersih Di Gedung Kantin Berlantai 3 PT Astra Daihatsu Motor.

[6] Tahara, Haruo., dan sularso. 2000. Pompa dan kompresor. Jakarta: PT. Pradaya Paramita

[7] Dietzel, Fritz. 1996. Turbin pompa dan kompresor. Aih Bahasa Dakso Sriyono. Jakarta: Erlangga.

[8] ASTM A53 Grade A dan B Standart Pipe Schedule 40.

[9] Selecting Centrifugal Pump. 2005. Frankenthal, Germany: KSB Aktiengesellschaft.

[10] SIRAWAN, Yudi. 2008. Sistem Pemipaan. Surabaya: Universitas Negeri Surabaya. 